\title{
O teatro, um campo de culturas que pesquisa uma linguagem perdida
}

\section{Resumo}

Artaud, que trabalha com a ideia do rito, nos afirma que o teatro é sempre um ato perigoso, um campo de culturas que pesquisa uma linguagem perdida, na qual o mundo está em constante recriação. Desta forma, o teatro deve recuperar o rito que, ainda segundo Artaud, é o lugar onde, através de um processo contínuo de transformações, se dá a reconstrução do corpo.

Palavras-chave: Artaud; rito, crueldade

\begin{abstract}
Artaud works with the idea of ritual. He states that theater is always a dangerous act, a field of cultures researching a lost language, where the world is in constant re-creation. Under such circumstances, theater must recover the ritual that, according to Artaud, is the place in which we reconstruct the body through a continuous transformation process.
\end{abstract}

Keywords: Artaud; Rite; Cruelty

Toda a produção artística de Artaud é formada apenas de rastros, vestígios, secreções. Ele afirma que o teatro é o "exercício de um ato terrível e perigoso". (VIRMAUX, 1978, p. 321) Assim, todo o seu trabalho tem a ver com a ideia do rito. Não como cópia, mas como entrega, como se quisesse fundar na cultura esse comprometimento. Vivenciar esse "perigo" é reconquistar uma ciência. Mas é um processo sempre de desorganização porque os afetos, quando essa experiência é vivida em sua intensidade, são retrabalhados.

Mas essa desorganização - que não é um surto nem uma experiência mística, antes uma experiência científica - é sempre programada. Porque o teatro é a ciência que tem o artista como foco. E o artista deve saber transitar nessa desorganização, porque para Artaud não existe diferença entre arte e vida, embora "o teatro continue a viver acima do real" (ARTAUD, 1995, p. 75).

\footnotetext{
1 Pesquisador, ator e dramaturgo. Doutorando em Pedagogia do Teatro e mestre em Artes Cênicas pela ECA/ USP, é co-fundador da Cia. de Teatro Os Satyros. Atualmente, acumula ainda o cargo de Diretor Executivo da SP Escola de Teatro - Centro de Formação das Artes do Palco, instituição que, ao lado de outros artistas e coletivos, sonhou e idealizou.
} 
Em "O Teatro de Séraphin", Artaud irá dizer que "no teatro, poesia e ciência devem identificar-se" (ARTAUD, 1999, p. 172). Por isso, ao apresentar o ritual, ele estará propondo a fabricação de uma pessoa ao afirmar que o teatro reconstrói o corpo, na medida em que "conhecer as localizações do corpo é refazer a cadeia mágica" (ARTAUD, 1999, p. 173).

Em sua obra, Artaud vai concluir que o teatro fala de uma linguagem secreta e, para chegar a suas questões, deve ser investigado. Para ele, o teatro é um campo de culturas que pesquisa uma linguagem perdida. Para isso, propõe a regressão, a volta às origens, colocando a cultura não apenas no âmbito estético, mas da sociedade. Analisa a criação e conclui que ela é um despedaçamento, a perda de algo, para a recriação vital do novo.

Artaud, quando usa o termo "crueldade", fala da crueldade metafísica. Para ele, o Teatro da Crueldade é uma maneira de fazer uma crítica sobre a cultura do espetáculo. É, portanto, um teatro que não se confina apenas ao palco, mas que possui a capacidade de se metamorfosear em qualquer situação, com o intuito de reelaborar um pensamento ou quebrar uma linguagem formal.

Porque, em geral, o discurso está sempre armado em sua formulação, faltando-lhe o confronto com a dúvida, o lugar onde o pensamento titubeia. Para Artaud, há, precisamente aí, uma crueldade que se confronta com o nascimento da linguagem.

Artaud vai negar a ideia de cultura enquanto produção. Para ele, a cultura é uma questão social mais urgente, em que o artista fala a partir da dor de sua existência, que ele irá denominar de impulso metafísico, que nasce de uma atitude interior e de uma experiência também ligada ao interno. E é isso que vai transformar o que ele chama de vida: uma atitude de desarmamento, uma maneira de se lançar ao desconhecido.

Mas crueldade também tem a ver com interrupção: com o automatizado, com o discurso pronto; a interrupção para a abertura de novos espaços que devem acontecer sempre antes da análise, da racionalização. Uma ruptura da cultura analgésica, portanto.

É dessa forma que o processo de criação aproxima-se sempre da angústia, onde os sentimentos estão ligados ao desconhecido. Onde se produz também a cultura das sensações - do imaginário, do sensível. É assim que o teatro atinge o sensorial, o intuitivo, numa experiência não apenas física.

Inimigo do sistema, Artaud acredita em um teatro que propõe maneiras de aprofundar a percepção como forma de desenvolvimento intelectual. E é no ritual, que 
está ligado à existência, que esta experiência acontece. Ali, no espaço circunscrito, a relação com o outro se configura.

O mundo está sendo sempre criado. O rito comemora isso: a criação. Mas é necessário reinventar o ritual no teatro - porque o ator tem o poder de ação sobre o espectador. Mas esse ator não representa, ele experiência. Só assim o fenômeno teatral é constituído como algo sagrado, vivenciado. Como um rito de passagem, uma instabilidade na qual a identidade é sempre dissolvida para depois ser reconstruída.

O rito abre outra relação com o tempo, que não é vivido de forma cronológica. Existe a ideia do eterno presente, o estado de suspensão. O ritual não tem necessariamente semelhanças com o ato cerimonial. Tem, sim, qualidade de ações: estar presente, inteiro, intenso:

A operação teatral de fazer ouro, pela imensidão dos conflitos que provoca, pela quantidade prodigiosa de forças que ela lança uma contra a outra e que convulsiona, pelo apelo a uma espécie de remistura essencial transbordante de consequências e sobrecarregada de espiritualidade, evoca, enfim, ao espírito, uma pureza absoluta e abstrata, após a qual nada mais existe e que poderíamos conceber como uma espécie de nota-limite, apanhada em pleno voo, e que seria como a parte orgânica de uma indescritível vibração (ARTAUD, 1999, p. 53).

O teatro deve superar o aspecto lúdico, apenas. É necessário que se chegue aos conflitos originários do ser humano, que estão congelados. E, para se chegar até aí, deve-se desmontar o organismo:

Porque o teatro não é essa parada cênica onde se desenvolve virtual e simbolicamente um mito mas esse cadinho de fogo e de verdadeira carne onde anatomicamente pela trituração de ossos, de membros e de sílaba s.o.s. corpos se refundem, e se apresenta fisicamente e ao natural o ato mítico de fazer um corpo. (VIRMAUX, 1978, p. 321)

Ao rito é dada a função de construir uma pessoa. Nele, o corpo passa por um processo contínuo de transformações, criando um espaço na nossa cultura para o reencontro.

No ritual, há sempre uma celebração festiva. Tem-se festa para celebrar o instante e para queimar o excesso. A cultura moderna esqueceu-se da festa no sentido de suspensão da atitude do controle. Artaud irá propor:

Um teatro que, abandonando a psicologia, narre o extraordinário, ponha em cena conflitos naturais, forças naturais e sutis, e que se apresente antes de tudo como uma excepcional força de derivação. Um teatro que produza transes, como as danças dos Dervixes e Aissauas, e que se dirija ao organismo com meios preciosos e com os mesmos meios que as músicas curativas de certos povos, que admiramos em discos, mas que somos incapazes de fazer nascer em nós. (ARTAUD, 1999, p. 93) 
Vivemos a sociedade do espetáculo e a arte, de modo geral, tem perdido sua relação com o rito. O espetáculo está em todos os segmentos de nossa sociedade: na economia, na política, no jornalismo, etc. A sociedade do espetáculo transforma todas as dimensões humanas em expressão teatral e secundariza o verdadeiro potencial transformador do teatro.

O teatro tem de encontrar seu lugar na sociedade pós-industrial, não através do mimetismo - teatro como cópia do social -, mas justamente através da sua não presença - aquilo que foi negado ao homem da sociedade contemporânea, mas vive dentro dele.

O que vem sendo negado pela sociedade é a dimensão da dor, do prazer como experiência plena, da desalienação. Também é negado o artesanal, o não lucrativo, o desinteressado. Essa deve ser a trilha de um teatro possível. Porque nela sobrevive a respiração fundamental do homem, a não ser esquecida jamais, porque nela sobrevive a arte do palco. Como sugere Artaud, necessitamos da arte primitiva, que depende de corpos e respirações, suores e cheiros humanos, exalações e presença sensual.

A concepção de ritual em Artaud está intimamente ligada ao surgimento do teatro na pólis grega. Margot Berthold cita o surgimento da tragédia grega em seu livro História Mundial do Teatro:

Duas correntes foram combinadas, dando luz à tragédia; uma delas provém
do legendário menestrel da Antiguidade remota, a outra dos ritos de fertilidade
dos sátiros dançantes. (...) Esses coros (de cantores com máscaras de bodes)
originalmente cantavam em homenagem ao herói Adrasto (...) e Sícion (...) Por
razões políticas, Clístenes, tirano de Sícion desde 596 a. C., transferiu tais coros
de bodes para o culto a Dioniso, o deus favorito do povo da Ática. Dioniso,
a encarnação da embriaguez e do arrebatamento, é o espírito selvagem do
contraste, a contradição extática da bem-aventurança e do horror. Ele éa fonte
da sensualidade e da crueldade, da vida procriadora e da destruição letal.
Essa dupla natureza do deus, um atributo mitológico, encontrou expressão
fundamental na tragédia grega. (BERTHOLD, 2001, p. 104)

A definição acima de Dioniso exprime a essência do Teatro da Crueldade artaudiano. O rito teatral de Artaud seria o ritual dionisíaco, fonte da tragédia clássica grega. Para os gregos, os festivais dionisíacos, nos quais o teatro acontecia, eram o grande momento do reencontro, da celebração do ressurgimento da vida. Dioniso despedaçado renascia, como a natureza e o homem, através desses rituais. Os gregos se identificavam, se reconheciam e reconstruíam suas vidas e seus corpos para o novo ano que se anunciava. A catarse aristotélica era o ápice desse movimento em que o ciclo da natureza e de Dioniso se reiniciava. 
Ainda para os gregos, a tragédia trabalhava com os ritos primitivos e falava das religiões que operavam com a ideia do sacrifício. Para eles, a religião não estava ligada apenas às suas relações com o bem e o mal, mas à vivência desse sacrifício.

No entanto, existem diferenças fundamentais. Em Aristóteles, o drama é pensado como organismo - unidade de ação, tempo e espaço. Para Artaud, é a decomposição desse organismo que interessa mais. Assim, trabalha-se sempre com uma obra em que é possível pregar uma experiência daquilo que não está codificado.

No rito artaudiano, o palco não imita nem simula uma representação. Nele, o presente não se repete. Ele, por si mesmo, é organizado por uma voz externa, seja do dramaturgo, do diretor ou dos próprios atores, e se dirige à pulsão sensitiva, que não será facilmente perceptível em uma vivência que não seja aprofundada sempre, em níveis cada vez maiores.

Artaud nos falará ainda sobre a importância da voracidade do olhar que precisa enxergar para ter um contato mais profundo. É imprescindível que esse rito trabalhe com a experiência do mistério através dos sentidos. Mesmo quando, nesse jogo, se desvendem todos os códigos. Porque, segundo ele: "As formas apoderam-se de seu sentido e de suas significações em todos os planos possíveis; ou, se quisermos, suas consequências vibratórias não são tiradas num único plano, mas em todos os planos do espírito ao mesmo tempo" (ARTAUD, 1999, p. 80).

O ritual só pode acontecer dentro de uma linguagem que faça com que todos os participantes, atores e espectadores, possam vivenciá-la, porque "O verdadeiro teatro nasce, aliás como a poesia mas por outras vias, de uma anarquia que se organiza, após lutas filosóficas que são o lado apaixonante dessas primitivas unificações" (ARTAUD, 1999, p. 82).

Embora horizontal, a linguagem é sempre construída no espaço, porém com hierarquias. Deve-se trabalhar sempre com a linguagem dos signos, das imagens, dos símbolos, porque é necessário reinventar ou recompor nossa cultura: "para o teatro, uma linha é um ruído, um movimento é uma música, e o gesto que emerge de um ruído é como uma palavra precisa numa frase" (VIRMAUX, 1978, p. 319).

Uma possibilidade é o trabalho com hieróglifos - elementos que são conhecidos, mas que levam as pessoas à experiência do desconhecido. Esse hieróglifo também pode ser um jogo - claro/escuro, vida/morte. É fundamental investir na experiência angustiante, em situações que não se consegue agarrar. 
Mas essa linguagem deve ser construída no espaço e não haverá necessariamente uma ligação entre códigos. Assim, desmembrar uma obra é decompô-la enquanto abertura. Dessa forma, o espetáculo, por si só, se dirige.

Um dos aspectos importantes na obra de Artaud é a questão da manifestação sonora, que é anterior à palavra. Porque, para se chegar a ela, há todo um caminho. Primeiramente, surge o balbuciar, o grunhido, o grito. E isso tudo é anterior à linguagem estruturada. O grito em Artaud está entre pensamento e gesto, palavra e corpo, e não está necessariamente ligado ao ato de gritar como expressão sonora, mas diretamente aos afetos, enquanto manifestação vital. Porque, para Artaud, "toda a criação provém da cena, encontra sua tradução e suas origens num impulso psíquico secreto que é a Palavra anterior às palavras." (ARTAUD, 1999, p. 63)

As questões que Artaud coloca já estavam em voga no seu tempo. Sua singularidade aparece dentro de um contexto. Para ele, o teatro pode ser de importância vital para a sociedade moderna. Não podemos nos esquecer de que sua geração viu surgir a comunicação de massa, passou pela revolução russa e também por duas guerras.

Artaud não compôs uma teoria sistemática, assim como Nietzsche. A geração que veio pós-Artaud é que pôde pensar métodos, procedimentos criativos. Ao nomear o Teatro da Crueldade, ele estava procurando mais do que um método: uma forma de sensibilizar e mobilizar pessoas para um novo teatro.

Talvez o que estivesse propondo Artaud em sua obra tenha a ver com um treinamento que dê possibilidade à espontaneidade. O psicólogo J. L. Moreno, que desenvolveu a Sociometria, irá dizer, mais tarde, que até mesmo a espontaneidade deve ser treinada: "a primeira pergunta: como é possível a produção da espontaneidade, pode ser respondida: pelo treino da espontaneidade". (MORENO, 1984, p. 71)

Mas atingimos um tempo em que a repetição, como treino, chegou à mecanização. Perdemos a espontaneidade e nossos gestos são apropriados e desencadeados por um processo em série.

Em nossos dias as instituições - família, fábrica, escola - estão em crise por causa da flexibilização dos mecanismos de poder. O trabalho se flexibilizou. Hoje, por exemplo, o computador permite que trabalhemos em um tempo e espaço diferentes.

A forma de controle sobre o indivíduo se sofistica, constantemente. Com isso, tem surgido, cada vez mais, o controle do tempo e do espaço, um processo historicamente recente. 
Artaud também nos sugere que, mais do que o espetáculo, o teatro é um agente social transformador que, ao negar o sempre-igual-da-lógica-do-lucro da Sociedade Pós-Industrial, aponta novos rumos para a convivência social.

Assim, podemos deduzir que o teatro é um espaço real, vivo, que atua na dinâmica social, com consequências evidentes no seu entorno, agindo sempre com a consciência dessa interferência direta que, como atividade, modifica em seu meio, revendo essa relação crítica e constantemente.

É esse, portanto, o teatro vislumbrado por Artaud, que propõe a desalienação e aponta para a reflexão crítica.

Neste sentido, estar alienado significa não estar pleno em si. O trabalhador que não se reconhece no fruto de seu trabalho está alienado. $E$, portanto, não é pleno. $A$ alienação está presente em quase todas as esferas do teatro, apesar de seu potencial desalienante.

O teatro tem de encontrar o lugar da desalienação; o espaço para nos libertar das amarras que nos encaixam em padrões sociais e que nos limitam a rótulos baratos. Somos uma multiplicidade de desejos e temores. Porque o teatro, como ritual, necessita colocar todos no palco, para que homens e mulheres possam resgatar a si próprios.

Por ser uma arte coletiva, o teatro implica num acordo de todos os artistas envolvidos em seu processo, em que todos se sintam possuidores de uma alma artista que, de uma forma ou de outra, se manifesta claramente na obra final. Nenhum artista é livre no palco se não se sentir livre para fazer as opções estéticas em seu processo. Desta maneira, o processo de trabalho será tão desalienante quanto o resultado deverá ser libertador.

Por fim, o ritual artaudiano é sempre uma experiência religiosa. Religião de acordo com sua definição filológica. Como no termo re-ligare, ou seja, re-ligar o indivíduo ao universal, ao deus onipresente.

Assim como o Dioniso grego buscava, não a individuação, mas a transgressão de seu próprio corpo, o estado de embriaguez que leva ao fim dos limites individuais, a experiência religiosa artaudiana buscava o fim do autocontrole para a total superação de si mesmo e a entrega ao fluxo do devir. Ou, como diria Nietzsche, a tragédia grega representa "o quebrantamento do indivíduo e sua unificação com o Ser primordial". (NIETZSCHE, 2001, p. 61) 


\section{Referências}

ARTAUD, Antonin. Linguagem e vida. São Paulo: Perspectiva, 1995.

O teatro e seu duplo. São Paulo: Martins Fontes, 1999.

BERTHOLD, Margot. História mundial do teatro. São Paulo: Perspectiva, 2001.

MORENO, J. L. O teatro da espontaneidade. São Paulo: Summus Editorial, 1984.

NIETZSCHE, Friedrich. O nascimento da tragédia. São Paulo: Companhia das Letras, 2001.

VIRMAUX, Alain. Artaud e o teatro. São Paulo: Perspectiva, 1978. 